\author{
Cadernos de \\ ESTUDOS LINGUIISTICOS - (59.3), Campinas, pp. 555-563 - set./dez. 2017
}

\title{
INDÍCIOS NA ESCRITA POPULAR
}

\author{
SÍRIO POSSENTI* \\ (UNICAMP/ CNPq/ FEsTA)
}

\begin{abstract}
RESUMO: O trabalho apresenta rapidamente bases para uma análise de "problemas" de ortografia na escrita de pessoas com letramento precário, sejam alunos em estágios iniciais, sejam cidadãos menos favorecidos economicamente. Os fatos ora sugerem processos que ocorrem com a língua - de variação, especialmente -, ora com os escreventes - hipóteses sobre a escrita, que, eventualmente, não coincidem com as regras definidas em lei, e que, por isso mesmo, servem de indícios que podem gerar hipóteses de análise, tanto de fatos da língua quanto de movimentos de interpretação dos escreventes.
\end{abstract}

Palavras-chave: ortografia - erros; escrita popular; variação; sotaques

ABSTRACT: The paper briefly provides a basis for an analysis of spelling "problems" in the writing of people with poor literacy, whether students in the early stages, or economically disadvantaged citizens. The facts now suggest processes that occur with the language, or with the writers - that is, they provide hypotheses about writing, which do not coincide with the rules defined in law, and, for this reason, serve as indications that can generate hypotheses of analysis. Keywords: spelling - errors; popular writing; variation; accents

\section{INTRODUÇÃO}

É bom que um texto cuja finalidade é homenagear uma colega trate de interesses comuns. Vou tentar um com esta característica.

Fui o primeiro orientado de Bernadete Abaurre. A relação decorreu de um curso de verão, no qual fui convertido às questões de fonologia (na verdade, mais a uma polêmica então viva). Sinceramente, eu não imaginava, àquela altura, que esta empreitada seria possível, dada minha trajetória anterior, mesmo a imediata.

Mais tarde, nos encontramos em trabalhos de fazer e corrigir provas - ela me convidava. Diversos interesses nos uniam, mas o laço mais óbvio era o interesse por textos humorísticos e por outros traços que eu diria "indiciários", nos quais descobríamos material de análise e de avaliação da competência linguageira em diversos compartimentos. Ainda hoje, vejo este tipo de interesse em sua página no facebook, especialmente nas tiras que fazem sua diversão e que são uma das formas de fazer seus seguidores olharem para a língua fora da sala de aula.

* Professor titular do Departamento de Linguística da UNICAMP, com atuação na área de Análise do Discurso.sirio@iel.unicamp.br 
Dado isto, penso que, nesta ocasião, posso homenagear Bernadete apresentando um pequeno pout-pourri a propósito de escrita. $\mathrm{O}$ estilo deste texto decorre de uma prática que pautou nossas relações de trabalho durante cerca de uma década - nessa atividade lateral de fazer provas. Melhor, um trabalho que se seguia a elas, especialmente em uma avaliação posterior, que acabava sendo publicada, pelo menos em parte, e que funcionava, ao mesmo tempo, como justificação técnica das grades de correção, e, especialmente, como material que as escolas poderiam levar em conta em suas práticas, já que se queria que tais provas (do vestibular Unicamp e outras) impactassem de alguma forma o ensino.

Nosso trabalho de escrita conjunta seguia uma rotina: eu fazia um primeiro esboço, que Bernadete fazia avançar; depois, negociávamos, palavra a palavra, a versão final. É o que, de certa forma, faço aqui (ou simulo): é um primeiro esboço que, eventualmente, se ainda lhe interessasse, Bernadete poderia levar adiante e dar ao texto um acabamento mais adequado.

Seguem-se, pois, algumas notas sobre escrita, que são indícios tanto de movimentos importantes da língua quanto dos sujeitos-falantes. ${ }^{1}$

\section{COMEÇO COM MATTOSO CÂMARA}

Foi lendo Mattoso Câmara que aprendi que os erros de grafia permitem ver fenômenos que estão ocorrendo na língua. Em vez de simplesmente corrigir, ou mesmo de estudar tais fatos à luz de alguma teoria mais sofisticada, é mais inteligente tentar compreender o que provoca os erros, isto é, quais são os fenômenos linguísticos que estão na base dos processos que levam alunos a escrever como escrevem, a errar exatamente como e onde erram e não de qualquer maneira ou em qualquer lugar.

Aprendi a ter um olhar menos raso em relação aos fatos da grafia lendo "Erros de escolares como sintomas de tendências linguísticas no português do Rio de Janeiro" (Câmara 1957), que analisa redações (e ditados) de estudantes (62 crianças de 11 a 13 anos) no antigo "Exame de Admissão" ao Ginásio. Os estudantes são da zona sul do Rio de Janeiro. Se fossem de outra região, diz Mattoso, os erros seriam em parte diferentes. Analisando erros que eles cometeram, o linguista de múltiplos interesses imagina que pode detectar tendências de mudança do português coloquial culto. Quando juntei as indicações deste texto com as proposições de Ginsburg (1986), pelas quais Bernadete fora seduzida já antes (e que conheci por indicação de uma orientanda dela), me convenci de que muitas coisas encontravam seu lugar. Convenci-me ainda mais quando tomei conhecimento de Pinto (1990) uma obra com grande número de dados e excelentes sugestões de análise.

${ }^{1}$ Dado que, durante muito tempo, escrevi colunas em sites, é deste material que recolho os dados que comento abaixo; eventualmente, vão junto fragmentos redigidos na ocasião. 
Mattoso elenca 20 fenômenos; os mais relevantes são:

1) em sílabas átonas, a oposição entre $e-i$ e entre $o-u$ se anula em favor de [i] e de [u], o que explica a ocorrência de formas escritas como acustumado (acostumado), sintiu-se (sentiu-se), traisueiro (traiçoeiro) e, por hipercorreção, de formas como romou (rumou). Com base nessa explicação, deveríamos entender que são absolutamente previsíveis erros como mininu; curuja etc., e também, por hipercorreção, menistro, etc. Observe-se que tais erros só ocorrem em sílabas átonas - nunca se vê uma grafia como "voci" por "você" (ouvintes / professores ficam um pouco embasbacados quando ouvem isso).

2) a nasalização do $i$ - inicial (por analogia a formas com prefixo in-) leva a formas como inquilíbrio e, por ultracorreção, a enquilibrio (equilíbrio)

3) redução ${ }^{2}$ de en- a in- produz formas como insolarados, imbarcação (ensolaradas, embarcação);

4) tendência a nasalar $u$ e $i$ finais (sicurijum, por sicuriju);

5) ausência de contraste entre [ow] e [o] produz loro (louro), mas também poupa e polpa (por popa), sendo que, nesse caso, há também neutralização de [1] e [w]. Mais exemplos: autas árvores (altas), causa azul (calça), a cobra siuvou no ar (por silvou), impusso (impulso), al longe (ao), ciovol (silvou) no ar e até mesmo silivou no ar (este, num esforço para manter o $l \ldots) ; 3$

6) ditongação de vogal diante de consoante fricativa: treis (três), mais (mas); por hipercorreção, trasçoeiro (traiçoeiro);

7) a "precariedade" de $l$ e $r$ intervocálicos produz sua intercalação em formas como tapúlio e tapúrio (tapuio), e até tatúlio, por assimilação das consoantes (ou seja, a um $\mathrm{t}$ se segue outro $\mathrm{t}$ );

8) também aparece tabuio, o que permite falar da famosa troca de letras, especialmente em posição intervocálica. A explicação é que se chega a confundir uma consoante surda intervocálica com uma consoante sonora, porque as vogais são sonoras. Assim,

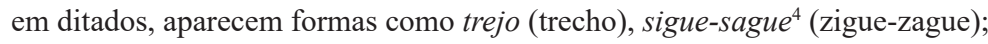

\footnotetext{
${ }^{2} \mathrm{Na}$ verdade, trata-se do mesmo fenômeno de alçamento descrito em 1), o que a hipercorrreção mencionada em 2) deixa claro.

${ }^{3}$ Observe-se que não se trata simplesmente de troca de $/ \mathbf{l} / \mathrm{e} / \mathbf{u} /$, mas de sua troca apenas em final de sílaba.

${ }^{4} \mathrm{O}$ mais interessante na análise deste fenômeno, - algo a ser mais bem avaliado - é que a"troca" de letras obedeça a uma diferença sutil: a surda se torna sonora entre vogais, como em trejo. Muitas análises - e diagnósticos de dislexia - deveriam ser refeitas à luz desta tese de Mattoso; a hipótese se torna mais forte porque sonoras se tornam surdas em contextos de surdez (sigue-sague) e também contíguas a nasais fazenta e pegando.
} 
9) formas como fazenta (fazenda), peganto (pegando), pentidos (pendidos), sincra (singra), um taqueles (um daqueles) se explicam pelo fato de a consoante ser forte depois de nasal (como o prova a palavra honra) $;^{5}$

10) desaparecimento do $r$ final: sincra (singrar), podiam-se (podiam ser) e, como sempre, por hipercorreção, ele estar (está) olhando, o rosto estar estampada uma alegria;

11) o artificialismo de contrações pronominais como "mo" leva a uma obsessão em não errar, o que produz formas como contar-mos.

12) a mesma falta de integração de morfemas na língua coloquial produz formas como deixa-ra, se ele passa-se (passasse), acorda-se (acordasse). ${ }^{6}$

A modalidade escrita costuma ser vista, muito mais comumente do que seria desejável, como se fosse a própria língua. Em relação a ela, concebida de fato como se, além de dever ser correta, fosse uniforme e natural (basta ver os argumentos invocados nos debates, quando surgem propostas de reforma ortográfica), analisam-se equivocadamente tanto a oralidade, marcada por características próprias, frequentemente tidas como defeitos, quanto as escritas populares, normalmente objeto de riso.

O que é mais claro do que qualquer outra coisa é que os juízos sobre as escritas "não oficiais" são em geral carentes de qualquer sofisticação. Vale a pena assinalar que os juízos correntes se chocam com uma experiência banal: a língua nos cerca o tempo todo, e, curiosamente, a tese mais arraigada que aprendemos sobre ela é que a usamos mal, que falamos errado. E os juízos sobre a precariedade da escrita são sólidos mesmo em uma sociedade pouco "letrada" como a nossa.

Já são muitos os estudos que seguem uma orientação contrária aos lugares comuns correntes, mas, como se dá também em outras áreas, eles não só não chegam ao "povo", como sequer afetam os letrados, os intelectuais, cujos juízos sobre escrita (e sobre língua, em geral) são idênticos aos dos iletrados, que, na verdade, os aprenderam dos letrados.

Os estudos relevantes sobre a questão são genericamente: a) os que têm como objeto a língua falada, analisando desempenhos reais, que mostram que a "lógica" dos textos falados é bastante diversa da dos textos escritos; o que fica bem claro também na sintaxe; b) os que tomam como objeto o processo de aquisição da escrita na escola e escritas populares ou de outras épocas; curiosamente, para os leigos, embora sejam originadas de sujeitos bastante diferentes, muitas características da escrita desses três grupos coincidem, especialmente no que se refere à representação de aspectos "problemáticos" da língua: a relação som / letra, mas também a divisão das palavras.

\footnotetext{
${ }^{5}$ Que "forte" seja ouvida como surda é outra questão interessante, que a fala cochichada (ausência de sonoridade) ajuda a esclarecer.

${ }^{6}$ Encontrei "Se um estrangeiro chegasse ontem ao Brasil e lê-se os principais jornais...", em artigo de Fernando Rodrigues, no jornal Folha de S. Paulo, de 06/03/2002. É razoável considerar o fato como indicando mais do que mera ignorância.
} 
As regras de grafia adotadas para uma língua são as que são em consequência de um conjunto de fatores históricos, sociais e políticos. Simplificando um pouco a questão, pode-se dizer que os erros de grafia são devidos a três ou quatro razões básicas:

a) a falta de uniformidade na correspondência entre som e letra (o que explica erros como escrever com j o que se deve escrever com $\mathbf{g}$, com ss o que se deve escrever com ç ou com sc etc.); erros deste tipo são comuns em "cartazes" e avisos como os que podem ser vistos em diversas seções, digitando "placas do meu Brasil, no google);

b) a diferença de pronúncia de certos segmentos (o que provoca a "troca" de e por $\mathbf{i}$, de $\mathbf{0}$ por $\mathbf{u}$, de $\mathbf{I}$ por $\mathbf{u}$, de $\mathbf{u}$ por $\mathbf{l}$, de $\mathbf{I}$ por $\mathbf{r}$, de $\mathbf{r}$ por $\mathbf{l}$ etc.);

c) variação mais ou menos significativa entre a forma dicionarizada da palavra e as formas faladas (por exemplo, eucaliptal e calipal ou calipar, choupo e chope, para citar regionalismos);

d) a questão da separação ou não de certas partículas (de que são exemplos porventura / de repente; em cima / embaixo; a partir / apesar etc.). Essa pequena amostra indica que quase nunca os erros são sintomas de "burrice", desinteresse ou de problemas de ordem médica, mas efeitos da variedade da representação escrita, trate-se da diversidade "legalizada", trate-se das diversas maneiras de falar a língua que se refletem de alguma forma na escrita.

Para ir direto ao ponto, diria que, em princípio, não há problema grave no que se refere a: a) letras que faltam; b) letras que sobram; c) letras trocadas; d) palavras que se separam e palavras que se juntam; e) acentos demais ou de menos; f) letras invertidas, em espelho etc. Claro que há trabalho para a escola, mas esses "erros" são completamente previsíveis no processo de aprendizado da escrita

Nas telas dos televisores, tivemos durante algum tempo (em torno de 96/97) um bom exemplo do prestígio e da relevância que nossa sociedade atribui à ortografia. Numa campanha da Unicef em favor de mudanças na educação, aparecia sobre a bandeira nacional a palavra "educasão", grafada assim, erradamente. Esse erro simbolizava o estágio problemático da nossa educação. Em seguida, apagava-se o erro e grafava-se corretamente a palavra, gesto que simbolizava as mudanças que levariam à eliminação dos problemas educacionais. Esse é apenas um exemplo de como a educação é associada ao domínio da ortografia correta.

Essa concepção merece comentários. Sempre que se discute a questão do ensino, em especial o ensino da língua, fala-se mais do que de qualquer coisa dos erros ortográficos. Penso que há para isso três razões:

1) o domínio da língua escrita (e não, p. ex., o domínio da história e da geografia) é a prova fundamental de escolaridade;

2) circula uma concepção equivocada de saber linguístico. Conforme certa ideologia, para que alguém seja considerado inteligente/sábio, é necessário que domine a ortografia (quando se quer caracterizar alguém como "ignorante", um dos recursos é apontar os erros de ortografia que comete). Como consequência, os erros ortográficos são considerados sérias deficiências. Chega-se a supor que os que os cometem têm problemas neurológicos graves. 
3) a ortografia é de fato um campo relativamente simples, no sentido de que os problemas podem ser classificados com bastante objetividade. Qualquer um pode saber ortografia ou resolver objetivamente os problemas, já que um dicionário resolve qualquer dúvida. Nesse sentido, é um saber quase sem sofisticação. É tanto uma questão de atenção quanto de prática. Além disso, os problemas se reduzem a poucas alternativas, ou seja, embora possa haver muitos erros, há poucos tipos de erros.

O domínio da ortografia é, ao contrário do que nossa sociedade "pensa", um saber nem tão relevante, exceto, como ficou dito, por seu valor simbólico. Mesmo assim, ou até por isso mesmo, dá prestígio. Também outros aspectos das línguas têm a ver com prestígio e não, por exemplo, com características estruturais e com funções comunicativas ou cognitivas. "Boa pronúncia" ou "boas concordâncias" produzem boas representações dos falantes. A chamada linguagem "correta" é associada à inteligência e à capacidade de raciocínio, e a linguagem "errada", à incapacidade. Em geral, sem qualquer fundamento. Pode-se conhecer muito ou ser muito ignorante falando em qualquer língua ou dialeto.

Nessa linha de valorização social de certos índices, a ortografia funciona como um distintivo: quem a conhece passa por sabido, quem não a conhece, por incapaz (não apenas ignorante, mas incapaz).

Por isso, nas escolas, insiste-se tanto na ortografia, especialmente nos primeiros anos de escola. Parece que pouco importa que se leia ou se escreva relativamente pouco. O importante é que um aluno não tenha problemas ortográficos. Alunos são reprovados aos milhares com base na ortografia que praticam, mesmo na fase de aprendizagem. E são cada vez mais numerosos os que são enviados a psicólogos e fonoaudiólogos, como se fossem doentes. Enquanto isso, outros milhares são aprovados apenas pelo fato de que aprenderam a não errar em suas "redações", frequentemente meras cópias dos pseudo-textos das cartilhas.

Há algum tempo, em reportagem de TV sobre possíveis problemas decorrentes de uma política escolar "sem reprovação", a mãe de um aluno dava um depoimento mostrando a "gravidade" da situação. O exemplo decisivo que ela fornecia era a grafia "serumano" (por "ser humano", em uma redação de seu filho, que cursava a quinta série). $\mathrm{O}$ caso merece pelo menos dois comentários: a) seria evidentemente desejável que esse aluno já estivesse escrevendo "ser humano"; b) por outro lado, essa mãe sabe que uma das mudanças decorrentes do acordo ortográfico é a grafia "superomem" - sem hífen e sem h - no lugar de "super-homem"? A diferença é pouca em relação ao erro do aluno. Certamente, essa mãe não sabe que há uma boa explicação para o erro de seu filho, e que erros assim são comuns; bastaria levar em conta que a pronúncia de sequências como "ser humano", os chamados vocábulos fonológicos, faz com que duas ou mais palavras sejam percebidas como se fossem uma só, como o atestam documentos históricos redigidos por pessoas letradas, antes de haver uma ortografia legalizada.

Exemplos, reais ou inventados, circulam na mídia. Em geral, fazem rir. Mas bastaria um conhecimento mínimo de fonologia, associados à consideração da variação linguística, para explicá-los facilmente. 
a) Um dos mais comentados é "séquiço" (ou "séquisso"), por "sexo". Esta grafia, que parece estapafúrdia, pode ser assim explicada: a) a pronúncia "cuidada” desta palavra é "sék-so", isto é, na fala, a divisão silábica não coincide com a divisão na escrita (que é $s e-x o$ ). Assim, na fala, a primeira sílaba se fecha com uma consoante oclusiva (k), e não com uma vogal.

b) há uma forte tendência, no português falado no Brasil, a acrescentar uma vogal nos casos em que as sílabas terminam em consoantes (em especial se oclusivas, mas também com outras obstruintes $-\mathbf{f} / \mathbf{v}, \mathbf{s} / \mathbf{z}$...). Daí as pronúncias correntes adivogado, opição, táquissi, e também áfita, por "afta", pisicologia por "psicologia", peneu por "pneu" etc. O mesmo princípio adapta palavras estrangeiras: "foot ball" > futebol. Com base nesses fatos, basta que o aluno ainda imagine que escrever ortograficamente seja transcrever sons e ele escreverá "séquiço" "séquisso". Eventualmente, os professores somos consultados sobre se aceitamos receber "anéquissos" junto às mensagens por e-mail. É difícil saber quando se trata de uma brincadeira.

O aluno que escreve assim, evidentemente, erra. Mas nem tudo são defeitos. Ele sabe, por exemplo, que as palavras proparoxítonas levam acento... E, especialmente, mostra que tem excelente ouvido, escreve com base no que ouve ou fala. O espantoso não é que ele erre, mas que erre a grafia de uma palavra conhecida, que ele encontra nos manuais de biologia, para dizer o mínimo.

\section{PLACAS}

Muitos talvez rissem do vendedor de guaraná (na Amazônia, talvez), mas deveriam - ou poderiam - ver também o que há de genial no erro cometido. No que importa, sua propaganda diz SERVIMOS SUCO NATURAL DO PÓ DO GUARANÁ. A FLÔR DE ZÍACO DO AMAZONAS.

O relevante, evidentemente, é AFLOR DEZÍACO, grafia para "afrodisíaco", à qual chegou, certamente depois de alguma análise, talvez de certa hesitação, o autor do cartaz (que deve ser meio antigo, porque ainda acentuou a palavra "flor"). Pode-se apenas rir da placa, como já disse. Mas também se pode tentar entender por quais caminhos chegou exatamente a essa grafia "errada". A segunda sílaba de "afrodisíaco" é correntemente pronunciada com uma tonicidade que a destaca, como a tônica de um "ator" em uma sequência como "ator perfeito". Tal sílaba, embora seja tônica, é pouco menos saliente do que a tônica de "perfeito" (é o tal acento secundário, do qual, evidentemente, nunca se fala na escola nem nos livros didáticos, nem nas gramáticas e nos dicionários).

Os estudantes de letras que têm a sorte de não repetir o colegial na Faculdade aprendem que sequências como "ator perfeito", "a escola", "minha história" etc. constituem vocábulos fonológicos. Mattoso Câmara usou exemplos como "ar roxo" (vs "arrocho") "hábil idade" (vs "habilidade") para esclarecer o conceito e para mostrar que os diversos graus de acento podem ser guias seguros na determinação de palavras, bem como para a explicação de junções de palavras que, de outra forma, não se explicariam (por exemplo, escritas como serhumano). 
Em resumo: a sílaba "fro" não é simplesmente átona ou tão átona quanto a sílaba "a" ou mesmo a sílaba "di" da palavra em questão. Sendo de alguma forma saliente, é percebida pelo autor da placa como uma palavra, a palavra "fro", variante de "flor". Por esse caminho, "afro" é analisada como "a frô", que ele sabe que se escreve "a flor" (ou, nas regras que ele conhece, "a flôr"). "Afrodisíaco" se torna assim "a flor de zíaco" (que "de" vire "di" não é necessário explicar, espero) como resultado de uma interpretação que dá sentido a uma palavra desconhecida, que parece uma expressão, um sintagma. Diante do que ouviu, o autor da placa deve ter pensado: “'afrô' eu sei como se escreve, o que eu não sei é o que significa 'zíaco', mas isso não é problema meu...”. É um bom exemplo de erro inteligente. É um erro, claro, mas é brilhante. Lembra as etimologias populares (aviso breve, assustar o cheque), tentativas de dar sentido a palavras ou a expressões opacas.

Pequena notícia de jornal informa que policiais de Santa Catarina identificaram um carro roubado porque tiveram sua atenção chamada pelo fato de que a grafia de Florianópolis da placa: os falsificadores escreveram FRORIANÓPOLIS.

O caso é um bom pretexto para falar da "troca de letras", um dos temas mais comuns nas escolas e em alguns consultórios. Casos assim podem dar cadeia, se quem os analisa é a Justiça, mas podem dar em desgraça de vários tipos se a avaliação for feita em sala de aula, em redações de alunos. Por exemplo, no site da TV Cultura, encontrei a seguinte passagem de uma das muitas aulas do professor Pasquale (ele se referia a questões de articulação de consoantes nasais e orais e surdas e sonoras):

"Quando esse mecanismo da fala está alterado, nós temos um fenômeno que é conhecido, atualmente, como dislalia ou distúrbio articulatório. Antigamente era chamado de rotacismo".

Se se trata do caso como um déficit cognitivo (do aluno, quando é do professor), o estudante é enviado a um consultório, mas o professor é inocentado. Uma análise da placa mostra coisa diferente: o caso é bom porque na grafia do nome dessa cidade a letra $\boldsymbol{l}$ aparece duas vezes, mas só foi trocada por $\mathbf{r}$ apenas uma vez pelos falsificadores. FLO se transforma em FRO, mas LIS continua sendo LIS (e jamais será RIS).

O que é que isso prova? Ou melhor: isso é um indício de quê? De que a troca só ocorre em posições fixas: no meio de sílaba e no seu final - ou seja, em sílabas do tipo FLO, CLO, FLA, FLE e como CAL, FAL, SOL (que pode se transformar em CAR, etc.) em palavras como calça, falso e solteiro. Mas nunca ocorre em sílabas do tipo LIS, LE, LA, LO, LOU etc. Por que alguém seria "dislálico" em um tipo de sílaba e não em outro?

\section{MAIS DADOS}

O leitor fica convidado - como se se tratasse de uma aula - a fazer por sua conta uma análise dos seguintes dados (encontrados em "Placas do meu Brasil"): 
- PASSEIOS A CAVALO NO MANGUESAU NAS FASENDAS ETC

- AMOLA: ALECATE E TEZORA

- VENDE-SE FILHOTES DE PIT BÚ

- VENDI:SI FONI XXXXXXXXXXX

- PROPRIEDADE PARTICULAR PROIBIDO ENTRADA DE PESSOAS CEM ALTORIZAÇÃO

- PROIBIDO CASAR E PESCAR

- PROIBIDO POR OBIGETOS NA MESA

- ADMITESE AOSILIAR DE COZINHA

\section{CONCLUINDO}

Nesta amostra, encontram-se soluções variadas para a escrita de cidadãos brasileiros. Algumas servem até para debater reformas da escrita. Outras, para ver fenômenos da língua. Outras, quase todas, para sugerir mudanças na escola, e, antes disso, nos currículos dos cursos de letras e de pedagogia. Se isso ocorresse, como no melhor dos mundos, de duas, uma: ou tais escritas desapareceriam um dia, como efeito de escolas mais eficazes; ou ninguém mais se divertiria com esses fatos, porque todos veriam neles bom material para uma análise interessante.

\section{REFERÊNCIAS BIBLIOGRÁFICAS}

GINSBURG, C. (1986). Sinais: raízes de um paradigma indiciário. In: Mitos, emblemas, sinais. São Paulo: Companhia das Letras. 1989. pp. 143-179.

MATTOSO CÂMARA. J. (1957) Erros de escolares como sintomas de tendências linguísticas no português do Rio de Janeiro. In Dispersos. Rio de Janeiro: Funda cão Getúlio Vargas, 1972. pp. 35-46.

PINTO, E. P. (1990). O português popular escrito. São Paulo: Editora Contexto. p. 94. 